\title{
Avaliação da Composição de Solo para Uso em Taipa Estudo de Caso
}

\author{
Edna Moura Pinto \\ George Santos Marinho \\ Bianca de Abreu Negreiros \\ Cintia Vieira \\ Felipe Amorim \\ Alain Henrique Souza
}

\section{Introdução}

O solo é um dos mais antigos materiais utilizados na edificação de inúmeros tipos de construçôes. Há cerca de 10 mil anos, ele mantém sua importância enquanto material construtivo, sendo na atualidade o responsável por cerca de $60 \%$ das habitações da população mundial. Embora haja uma ideia comum de que essas edificaçóes só existam em países em desenvolvimento, na Europa, elas compóem a paisagem de países como Suécia, Dinamarca, Alemanha, Inglaterra, Espanha, Portugal e França, onde aproximadamente 15\% da população vive em habitaçôes feitas em taipa ou adobe (RICARDO, 2003).

No Brasil, o solo se firma como importante material construtivo desde o período colonial e atualmente sua importância, ainda que menos exaltada, permanece. Somente no estado do Ceará, mais de 70 mil habitaçôes populares fazem uso da terra como material de construção, o que evidencia a importância desse material construtivo em relação à história e à tradição, não somente do Nordeste, como também do Brasil.

A utilização do solo como material de construção faz uso de diferentes técnicas de acordo com as disponibilidades e necessidades de cada local. Dentre elas, as mais conhecidas são: a taipa de mão, a taipa de pilão, a taipa de sebe, a taipa de sopapo, a taipa leve, o adobe, e, mais recentemente, o 
superadobe, o PISE (Terra Estabilizada Compactada Pneumaticamente), o hiperadobe e o COB.

Com o advento da revolução industrial, tais práticas construtivas foram preteridas frente ao surgimento de novos métodos de construção, que contribuíram para a substituição da arquitetura de terra por sistemas e materiais com melhor padronização e racionalização, visando atender as demandas da nova sociedade industrial e suas cidades em transformação.

Não tardou para que o uso do solo entrasse em um processo de decaimento. Em nosso país, atualmente, ele é empregado quase exclusivamente em habitaçôes carentes, sem acompanhamento técnico ou qualidade. Por esse motivo, é constantemente associado à construções com qualidade inferior, não duráveis, insalubres e desprovidas de apreciação arquitetônica.

"A existência de uma vasta literatura acerca das boas práticas construtivas com o uso do solo faz parecer que não há mais nada o que se dizer sobre o assunto. Porém, a prevalência de técnicas negligentes na etapa construtivas e a ausência de métodos efetivos na aferição da qualidade mostram que ainda existe campo de estudo para esse método de construção."

Entretanto, o uso do solo na construção pode apresentar um bom desempenho quando a técnica é utilizada corretamente. Nesse contexto, fazse importante a pesquisa orientada para a melhora da qualidade técnica das habitaçóes com solo, uma vez que "A maior parte das patologias identificadas já foram estudadas e atualmente tem respostas" (SILVA, 2001, p. 63). Tais soluçóes, contudo, não foram dadas a partir de inquietaçóes recentes, as primeiras notícias sobre pesquisas com construção de terra datam da revolução francesa, ocorrida em 1789, por meio da figura de François Conteraux (SILVA, 2001, p. 65 apud DETHIER, 1993).

\section{A Taipa de Sebe}

Como observado, várias são as técnicas para uso do solo em construçôes. Nossa abordagem aqui se fará sobre a taipa, considerando as vantagens do uso dessa matéria prima, mas com foco em evitar ou minimizar o que lhe confere desvantagem.

$\mathrm{O}$ que denominamos taipa compartilha de outras denominaçóes sinonímias. No livro Arquitetura popular brasileira, Wainer (2012) descreve 3 denominaçóes: a taipa de mão, a de sebe e a de sopapo como técnicas 
diferentes entre si. A técnica aqui apresentada corresponde à taipa de sebe, descrita pelo autor como aquela na qual o barro é aplicado sobre uma trama de varas, ripas ou gravetos.

A taipa consiste tipicamente em um entramado ortogonal feito com madeira roliça ou serrada, com intervalos regulares e espaçamento estimado entre 5 a $20 \mathrm{~cm}$ (PISANI, 2006) fixados em esteios/estacas por meio de fibra de sisal, cipó, arame ou pregos,, que ao fim de recebe o preenchimento com terra. A trama pode apresentar-se em diferentes conformaçóes,.A Figura 1 ilustra três tipos de estrutura: A: Único; B: Alternado e C: Paralelo.

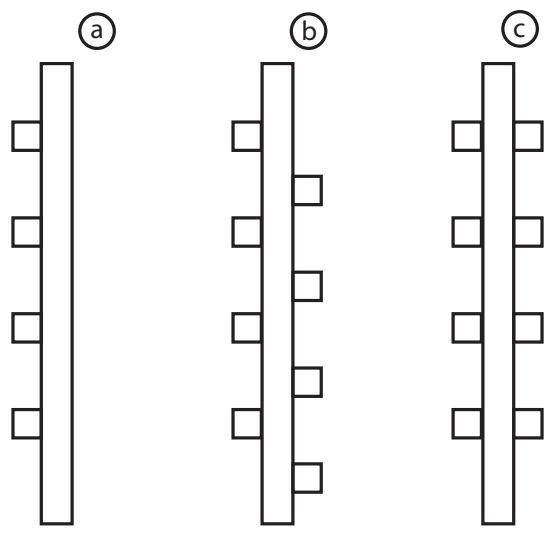

Figura 1. Tipologias de fixação das ripas. A: Único; B: Alternado e C: Paralelo.

Os esteios nos quais os tramos são fixados e os demais apoios verticais são normalmente enterrados diretamente no solo, à profundidade variável. A espessura final das paredes costuma variar entre 15 e $20 \mathrm{~cm}$.

\section{Fragilidades do Sistema}

Por meio da observação de uma experiência construtiva realizada na cidade de João Câmara/RN, que na década de 80 foi acometida de fortes abalos sísmicos, iniciados em agosto de 1986.

A série de abalos sísmicos resultou em danos a mais de 4.000 edificaçóes, em sua maioria residências, localizadas tanto na zona urbana como na zona rural. Nesse período, o Exército Brasileiro foi responsável por realizar estudos que tinham o objetivo de criar projetos para edificaçóes resistentes, a fim de possibilitar a reconstrução de habitações parcialmente ou totalmente colapsadas 
pela ação de abalos sísmicos de até 5.3 graus Richter. O Ministério do Interior (MINTER) abriu uma comissão especial (Portaria no 28/MINTER de 3/2/1987) que realizou um relatório de necessidades físicas e financeiras para a área, viabilizando um plano de reconstrução/recuperação das edificaçóes baseado no emprego da taipa com painéis pré-fabricados. O projeto Taipa proporcionou aos habitantes locais o uso de financiamento governamental e emprego de mão de obra do batalhão de Engenharia do Exército. Uma melhor descrição dos aspectos construtivos do projeto podem ser consultados em Veloso (2012), Pinto et al. (2013), Dantas (2002).

A realização de entrevistas e visitas in loco (Figura 2a) possibilitaram apontar as principais manifestaçôes patológicas das edificaçôes remanescentes ao longo de quase 30 anos, bem como a descrição das tipologias empregadas no projeto (2b) e a identificação de potenciais contribuições que essa experiência poderia somar a uma avaliação de sistema construtivo com foco nas soluçóes de projeto.

A proposta-fabricaçáo dos painéis vislumbrava a racionalização construtiva por meio da adoção de painéis modulados (figura 2c) e optava por critérios capazes de determinar a correta composição do solo empregado na vedação, como poderemos constatar nessa investigação, ainda assim não pôde impedir a ação de desgastes e o surgimento de manifestaçôes patológicas ao longo do tempo (figura 2d).
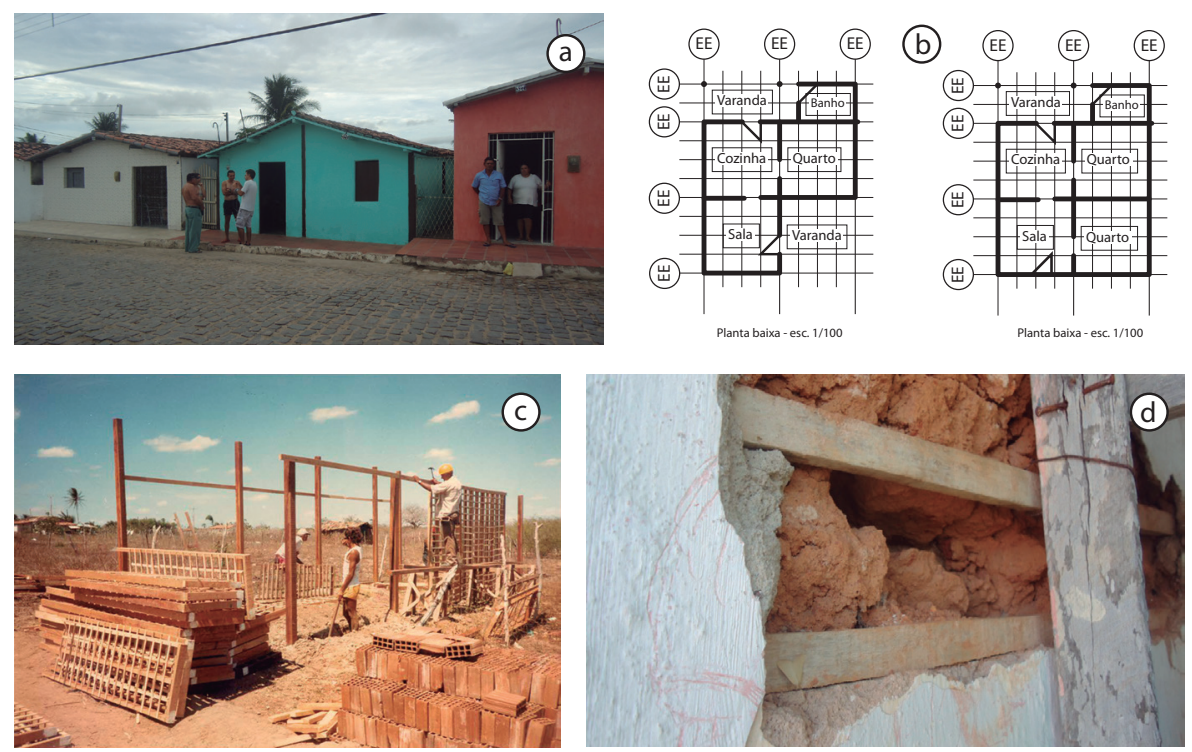

Figura 2. $O$ estudo de caso do projeto Taipa em João Câmara/RN. 
A partir da descrição dessas manifestaçôes patológicas, apresentas na figura 3 , podemos identificar aquelas que acometem com frequência as paredes (frestas, descolamento, deformaçóes) e o madeiramento (umidade, ataque de xilófagos). Tais patologias podem ser facilmente descritas e identificadas em literaturas sobre o tema, alguns estudos discutem as causas e soluçóes para esses problemas.

De modo claro, a execução inadequada das vedaçôes em terra pode conduzir a um efeito em cadeia, comprometendo a durabilidade dos outros componentes empregados (ARAÚJO, 2007). Por exemplo, a exposição do tramo de madeira, decorrente das frestas no reboco, promove o apodrecimento da estrutura e a consolidação de vetores de doenças nas frestas, como o omo o barbeiro, inseto transmissor do protozoário que causa a doença de Chagas; ratos e baratas." Portanto, a preocupação com a qualidade do solo utilizado para preenchimento e cobertura do tramo deve ser tratada como questáo de segurança estrutural e saúde pública.

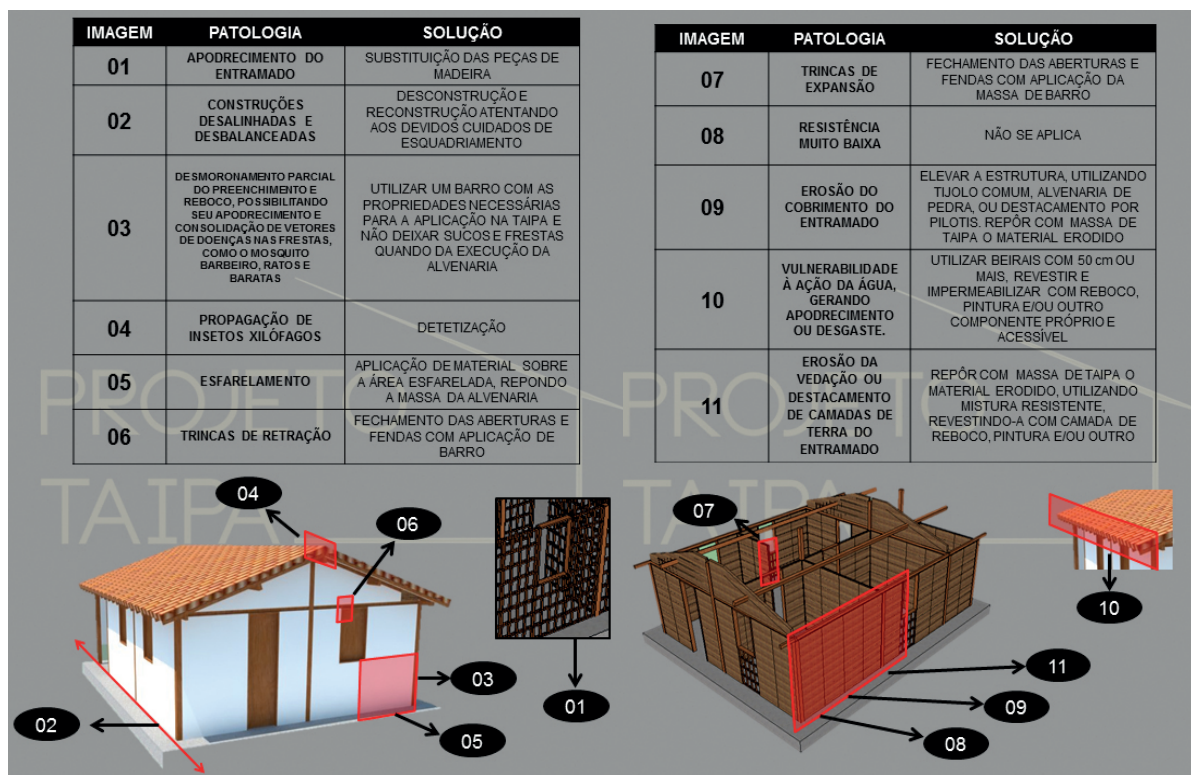

Figura 3. Manifestações patológicas na edificação em Taipa - João Câmara/RN.

Uma construção em taipa bem executada irá exigir especial atenção com a qualidade do solo, ele é o fator que mais contribui para a durabilidade e 
tem como principais constituintes a argila, a areia e o silte. A argila exerce influência no desempenho mecânico do solo, ela garante coesão e alguma resistência à ação da água. No entanto, um solo com demasiada argila pode gerar trincas durante a secagem, devido à efeitos de retração. Desse modo, é necessário otimizar sua composição. A dosagem correta de seus constituintes é o que se deve almejar para tornar o material adequado.

É recomendado, sempre que possível, a realização de testes em laboratório para a identificação da qualidade do solo utilizado na taipa. No entanto, essa realidade não é acessível a todas as situações e, nos casos em que não é possível a realização de ensaios laboratoriais, são indicados vários métodos alternativos (DOAT et al., 1979), (CEPED, 1984), (HUNTER et al., 2004), (MINKE, 2006).

Aliada ao uso correto do material é imprescindível a manutenção periódica para assegurar a integridade dos componentes. Embora não seja foco desse estudo de caso, pode-se perceber que as casas em melhor estado de conservaçáo passavam por manutenção à medida que as patologias surgiam, com exceção da pintura que era realizada com periodicidade de aproximadamente um a dois anos.

Em João Câmara, o preenchimento das paredes foi realizado com solo obtido nas proximidades da cidade, no distrito de Queimadas/RN. Para aplicação, ele foi previamente amassado com os pés e posteriormente aplicado com as mãos, a fim de cobrir toda ripa de madeira do painel. Após a secagem do barro, as paredes foram rebocadas com massa única constituída de uma mistura de argamassa de cimento, cal, barro e areia (traço de 1:3:7:1/2) - à exceção do sanitário, no qual é executada uma barra lisa de cimento queimado (traço 1:3 de cimento e areia) para impermeabilização da parede na área molhada. Com o reboco seco, todas as paredes (internas e externas) eram finalizadas com a pintura em duas demãos de cal.

As especificaçóes técnicas previstas em memorial nos levam a ponderar sobre a busca pela qualidade do solo empregado como premissa. Mas, embora todas as edificaçóes fizessem uso de matéria prima comum, algumas edificações foram encontradas em estado precário. O que certamente está relacionado a outras variáveis a serem consideradas caso o solo seja comprovadamente adequado ao uso. 


\section{Procedimentos para Avaliação da Qualidade do Solo Utilizado no Estudo de Caso}

Para se ter uma noção da adequação do material de revestimento submetido ao intemperismo de quase 30 anos, foram realizados ensaios tanto em amostras colhidas no local de extração da matéria prima no barreiro situado na regiáo de Queimadas - $\mathrm{RN}$, denominada amostra A, quanto em amostras retiradas de uma edificação em estado de conservação crítico, identificada como amostra B.

Durante o desenvolvimento deste trabalho, foram efetuadas visitas in loco para levantamento de dados, realização de entrevistas com moradores e participantes do processo construtivo e coleta de amostras do material. De posse das amostras, foram realizadas as seguintes análises: difração de raios x, granulometria (com base na norma NBR 7181:1984), limite de liquidez (de acordo com a norma NBR 6459:1984), limite de plasticidade (conforme recomendaçóes da norma NBR 7180:1984) e massa específica (segundo a norma NBR 6508:1984). Com base nos resultados das análises, procedeu-se o estudo das propriedades físicas, químicas e mecânicas do material construtivo.

\subsection{Preparação das Amostras}

A amostra A foi reunida às amostras retiradas da habitação, e ambas foram submetidas a um processo de secagem ao ar livre. Depois, foram quarteadas e transportadas em bandejas para secagem em estufa. Após a secagem, foram manualmente desagregadas com ajuda de um almofariz e pistilo de porcelana, de acordo com recomendaçôes da norma NBR 6457:1986 - Preparação para ensaios de compactação e ensaios de caracterização através do processo de secagem prévia. Para realizar os ensaios de caracterização, uma alíquota de cada amostra foi destinada ao Laboratório de Cerâmica - DEMAT / UFRN e ao Laboratório de Mecânica dos Solos, do Núcleo Tecnológico Industrial da UFRN.

\subsection{Análise Química por Fluorescência de Raios X}

A análise química foi realizada empregando-se a técnica de fluorescência de raios X. Nesse processo, utilizou-se o espectrômetro de fluorescência de raios X por energia dispersiva (Shimadzu EDX-720/800HS), pertencente 
ao Laboratório de Difratometria de Raios X do Centro de Tecnologia da UFRN - INFRA/LIEM.

\subsection{Análise Mineralógica por Difração de Raios $X$}

Para análise mineralógica da amostras, empregou-se o Difratômetro de Raios X (Shimadzu XRD 7000) com goniômetro Theta-Theta, pertencente ao Laboratório de Engenharia de Materiais da UFRN.

\subsection{Análise Granulométrica}

A análise granulométrica consiste na determinação das dimensões das partículas que constituem as amostras e no tratamento estatístico dessa informação. No caso de sedimentos grosseiros, o método mais utilizado é o da peneiração. A peneira para este tipo de análise consiste de um suporte cilíndrico metálico (latão, alumínio, inox, etc.) dotado de uma rede (geralmente metálica, mas que, em alguns casos, pode ser de outro material, como plástico) de malha calibrada. Neste trabalho, foram determinadas as dimensões das partículas individuais e estudada a distribuição pelo peso, volume e número de partículas integradas de cada classe dimensional considerada, seguindo-se as recomendaçóes da NBR 7181:1984.

A aparelhagem necessária foi constituída de balança (faixa de peso nominal entre $0,2 \mathrm{~kg}$ e $10 \mathrm{~kg}$ e resolução entre $0,01 \mathrm{~g} \mathrm{e} 1 \mathrm{~g}$ ); recipientes para repouso da amostra; estufa capaz de manter a temperatura entre $60^{\circ} \mathrm{C}$ e $65^{\circ} \mathrm{C}$ e entre $105^{\circ} \mathrm{C}$ e $110^{\circ} \mathrm{C}$; aparelho de dispersão; proveta de vidro; densímetro de bulbo simétrico (calibrado a $20^{\circ} \mathrm{C}$, com resolução de $0,001 \mathrm{~g} / \mathrm{cm}^{3}$ ) com escala de graduação variando entre $0{ }^{\circ} \mathrm{Ce} 50^{\circ} \mathrm{C}$ e divisão de $0,1^{\circ} \mathrm{C}$; relógio com indicação de segundos; béquer de vidro; proveta de vidro; tanque para banho; peneiras (50; 38; 25; 9,5;4,8; 2,0;0,6;0,42; 0,$25 ; 0,15$ e $0,075 \mathrm{~mm})$; escova com cerdas metálicas; agitador mecânico de peneiras; baqueta de vidro e bisnaga.

Os ensaios de granulometria foram divididos em duas partes: análise por peneiramento e análise por sedimentação. Os solos grossos (areias e pedregulhos), possuindo pouca ou nenhuma quantidade de finos, podem ter a sua curva granulométrica inteiramente determinada utilizando-se somente o peneiramento. Em solos com quantidades significativas de finos, deve-se realizar o ensaio de granulometria conjunta, que engloba as fases de peneiramento e sedimentaçáo. Com base nos resultados obtidos nesse ensaio, 
obtém-se a curva de distribuição granulométrica, tendo no eixo das ordenadas (escala aritmética) as porcentagens das partículas e no eixo das abscissas (escala logarítmica) os diâmetros das partículas (em mm). Denominações específicas são empregadas para diversas faixas de tamanho de grãos. No sistema de classificação adotado pela ABNT - Associação Brasileira de Normas Técnicas, assumem-se os valores indicados na tabela 1 .

Tabela 1. Classificação dos grãos.

\begin{tabular}{ll}
\hline Classificação & Diâmetro dos grãos \\
\hline Argila & Menor que $0,002 \mathrm{~mm}$ \\
\hline Silte & Entre 0,06 e $0,002 \mathrm{~mm}$ \\
\hline Areia & Entre 2,00 e $0,06 \mathrm{~mm}$ \\
\hline Pedregulho & Entre 60,0 e $2,0 \mathrm{~mm}$ \\
\hline
\end{tabular}

Fonte: NBR 7181:1984.

Foram utilizados cerca de $70 \mathrm{~g}$ da amostra peneirada, na qual os grãos maiores, relativos aos pedregulhos, foram retidos, diluídos em solução de água destilada com defloculante e dispersados. Após a sedimentação (em 4, 8, 15 e 30 minutos, e 1, 2, 4, 8 e 24 horas), a amostra foi separada em suas fraçóes de areia (grossa, média e fina) pela sequência de peneiras de 1,2;0,6;0,42;0,25 e 0,15 . A fração de argila foi obtida por meio da menor peneira $(0,075$; \#200), que foi separada do silte.

\subsection{Limites de Liquidez (LL) e de Plasticidade (LP)}

As análises dos Limites de Liquidez (LL) e de Plasticidade (LP) são importantes porque estáo diretamente relacionados à trabalhabilidade dos materiais e à variação de volume e absorção de água (LIMA, 2010). Por se tratar de índices de consistência, a determinação desses limites se baseia na constatação dos diferentes aspectos do solo argiloso, de acordo com seu teor de umidade. Além disso, as análises também permitem determinar o Índice de Plasticidade (IP), referente à faixa de valores em que o solo se apresenta plástico. A partir da determinação dos limites de Atterberg e seguindo-se as recomendaçôes das normas NBR 6459:1984 - Determinação do Limite de Liquidez e NBR 7180:1984 - Determinação do Limite de Plasticidade, foram determinadas a plasticidade do solo e seus limites de consistência. Os ensaios foram realizados no Laboratório de Mecânica dos Solos da UFRN. 
O Limite de Liquidez (LL) é definido como aquele em que o teor de umidade do solo admite a abertura de uma ranhura mediante 25 golpes para se fechar na concha do aparelho Casagrande. Neste trabalho, os ensaios para determinação do Limite de Liquidez (LL) foram realizados em conformidade com a NBR 6459:1984. Utilizou-se um aparelho denominado "Casagrande", composto de uma base de ebonite, um conjunto concha e guia do excêntrico, cinzel, uma esfera de aço ( $8 \mathrm{~mm}$ diâmetro), um gabarito, espátula de lâmina flexível (com $80 \mathrm{~mm}$ de comprimento), cápsula de porcelana (com $120 \mathrm{~mm}$ de diâmetro), balança (com resolução de $0,01 \mathrm{~g}$ ), recipientes para repouso da amostra e estufa (capaz de manter a temperatura dentro das faixas de $60{ }^{\circ} \mathrm{C}$ a $65^{\circ} \mathrm{C}$ e de $105^{\circ} \mathrm{C}$ a $110{ }^{\circ} \mathrm{C}$ ). Os ensaios somente são executados após verificação dos seguintes itens: eliminação de folga na conexão dos pinos; inexistência de ranhuras na concha; integridade do cinzel; e ajuste do ponto de contato da base da concha (10 $\mathrm{mm}$ acima da base).

O Limite de Liquidez (LL) é o grau de umidade do solo, determinado pelo aparelho "Casagrande". O dispositivo é constituído de uma concha metálica acoplada a uma manivela. Quando movimentada, a manivela desloca a concha, fazendo-a cair sobre uma base sólida. São necessários de 15 a 35 golpes para se conseguir o fechamento da ranhura central padrão de $13 \mathrm{~mm}$, feita previamente no solo colocado na concha - metade da amostra, previamente seca e homogeneizada com água destilada. O Limite de Liquidez equivale ao teor de umidade em que a ranhura se fecha com 25 golpes. De acordo com a norma NBR 6459:1984, o LL percentual é obtido por meio da seguinte relação:

$$
\text { Águade esfaleramento }=\frac{\text { massaúmida }- \text { massa seca }}{\text { massa seca }} \times 100
$$

Os gráficos construídos a partir dos resultados obtidos nos ensaios contêm o número de golpes, no eixo das ordenadas (escala logarítmica), e o teor de umidade, no eixo das abscissas (escala aritmética). Dessa forma, gera-se uma reta que permite encontrar o valor aproximado da umidade (expresso em porcentagem) correspondente a 25 golpes (Limite de Liquidez).

O Limite de Plasticidade (LP) é o grau de umidade necessário e suficiente para deslizar sobre uma placa de vidro uma porção de $10 \mathrm{~g}$ da amostra do solo umedecido e homogeneizado com água destilada, até formar um pequeno cordão com $3 \mathrm{~mm}$ de diâmetro e cerca de $100 \mathrm{~mm}$ de comprimento. Dele, 
são retiradas partes para determinação da umidade da amostra. No presente estudo, os ensaios de determinação do Limite de Plasticidade (LP) foram realizados seguido-se as recomendaçôes da norma NBR 7180:1984. Os ensaios foram realizados no Laboratório de Mecânica dos Solos da UFRN, contando-se com a seguinte aparelhagem: placa de vidro de superfície esmerilhada (30 cm de lado), gabarito cilíndrico, espátula de lâmina flexível (80 mm de comprimento), cápsula de porcelana (120 mm diâmetro), balança (resoluçáo 0,01g), recipientes adequados para repouso da amostra e estufa (capaz de manter a temperatura de $60^{\circ}$ a $65^{\circ}$ e $105^{\circ}$ a $110^{\circ}$ ). De acordo com a norma NBR 7180:1984, o valor do LP é dado pela seguinte relação:

$$
\text { Águade esfaleramento }=\frac{\text { massaúmida }- \text { massa seca }}{\text { massa seca }} \times 100
$$

O Índice de Plasticidade (IP) é definido como o intervalo de umidade em que o material apresenta plasticidade. Pode ser determinado de dois modos: pela diferença entre os limites de liquidez e de plasticidade.

$$
I P=L L-L P
$$

ou pela relação estabelecida na norma ABNT / NBR 7180:1984,

$$
I P=\% \text { de umidade a } 25 \text { golpes-água de esfarelamento }
$$

Em geral, os limites de liquidez e de plasticidade dependem da quantidade e do tipo de argila presente no solo. O índice de plasticidade, entretanto, é dependente apenas da quantidade de argila. Na prática, o solo pode ser caracterizado pelo seu índice de plasticidade e seu limite de liquidez.

\subsection{Massa Específica}

Os ensaios de determinação da massa específica dos solos foram realizados no Laboratório de Engenharia de Materiais da UFRN, seguindo-se as recomendaçóes da norma NBR 6508:1984.

\section{Resultados e Discussões}

Fundamentados nos procedimentos descritos, foram realizados os ensaios para coleta dos dados necessários às análises atinentes ao estudo desenvolvido, cujos resultados são apresentados a seguir. 


\subsection{Análise Granulométrica}

$\mathrm{Na}$ etapa de peneiramento, constatou-se que os resultados foram muito similares: amostra $A=25,90 \%$ e amostra $B=25,55 \%$, ver tabela 2 . No entanto, sabendo-se que a peneira \# $200(0,075 \mathrm{~mm})$ é a mais fina e permite a separação entre o silte (retido) e a argila (passa), a comparação entre o silte retido na peneira evidenciou melhor a diferença entre as amostras, visto que a primeira amostra tinha $18,00 \mathrm{~g}$ enquanto a segunda tinha $10,10 \mathrm{~g}$, desse modo a amostra A apresenta solo com um conteúdo de silte ligeiramente maior.

Tabela 2. Resultados do peneiramento.

\begin{tabular}{llllll}
\hline Peneiras & \multicolumn{3}{l}{ Amostra A } & Amostra B \\
\hline$\#$ & $\mathbf{m m}$ & $\begin{array}{l}\text { Massa retida } \\
(\mathbf{g})\end{array}$ & \% P passa & $\begin{array}{l}\text { Massa retida } \\
\mathbf{( g )}\end{array}$ & \% P passa \\
\hline & 25 & 0 & 100,00 & 0 & 100,00 \\
\hline & 19 & 0 & 100,00 & 0 & 100,00 \\
\hline & 9,50 & 1,7 & 99,89 & 0 & 100,00 \\
\hline 4 & 4,80 & 15,8 & 98,83 & 3,7 & 99,75 \\
\hline 10 & 2,00 & 27,90 & 96,95 & 66,70 & 95,22 \\
\hline 16 & 1,20 & 1,20 & 95,78 & 3,10 & 92,22 \\
\hline 30 & 0,60 & 8,40 & 87,58 & 16,80 & 75,94 \\
\hline 50 & 0,42 & 7,40 & 80,36 & 11,20 & 65,09 \\
\hline 100 & 0,30 & 8,50 & 72,06 & 10,40 & 55,01 \\
\hline 200 & 0,15 & 29,30 & 43,47 & 20,30 & 35,34 \\
\hline & 0,075 & 18,00 & 25,90 & 10,10 & 25,55 \\
\hline
\end{tabular}

Observando-se os gráficos apresentados nas figuras 4 e 5, percebe-se que, apesar de semelhantes, a curva relativa à amostra $\mathrm{B}$ apresentou maior elevação na parte de silte e areia fina. 


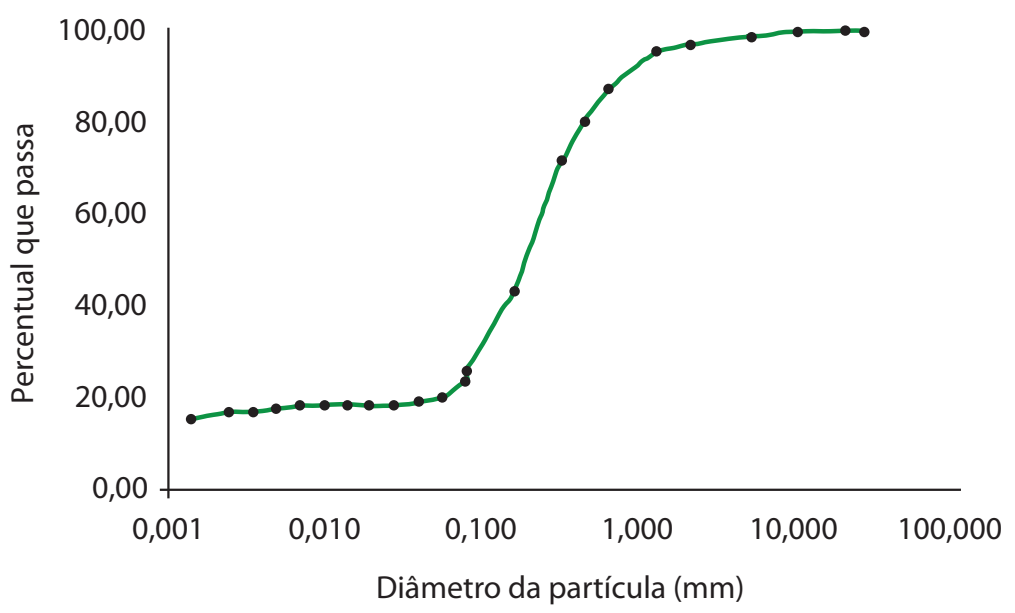

Figura 4. Curva de granulometria - amostra A.

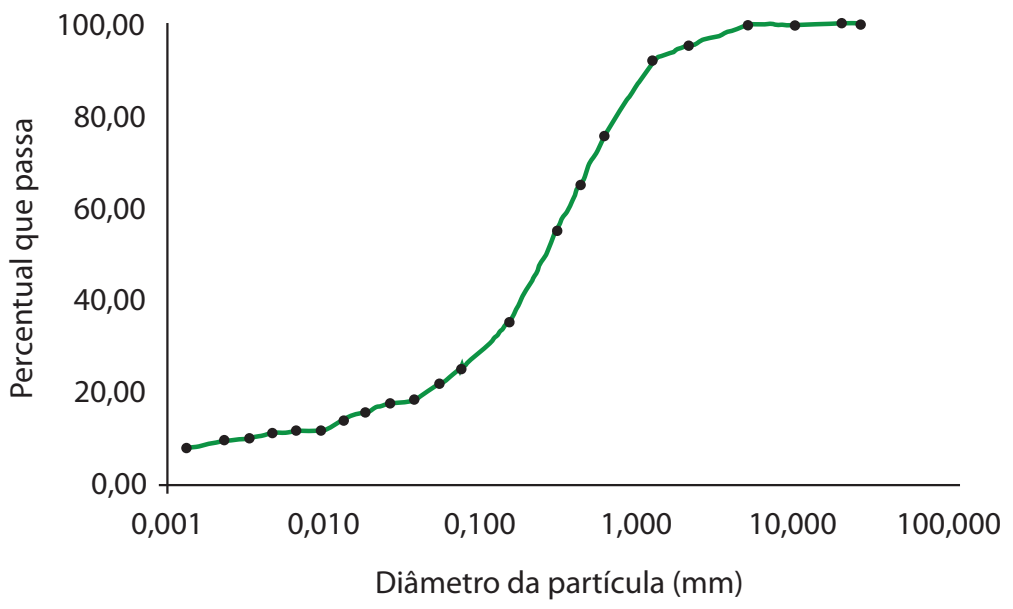

Figura 5. Curva de granulometria-amostra B.

\subsection{Sedimentação}

A etapa de sedimentação, baseada na Lei de Stokes, mede diretamente a distribuição de sedimentos, em função do tempo necessário para essas partículas se sedimentarem em uma célula vertical ou centrífuga com um líquido conveniente. A velocidade de sedimentação de cada partícula é proporcional à diferença de densidade em relação ao meio e ao quadrado 
do seu diâmetro. $\mathrm{Na}$ tabela 3, apresentam-se os resultados dos ensaios de sedimentação.

Tabela 3. Resultado da sedimentação.

\begin{tabular}{lll}
\hline \multicolumn{3}{l}{ \% P passa $(<\mathrm{Di})$} \\
\hline Tempo $(\mathrm{min})$ & Amostra A & Amostra B \\
\hline 0,5 & 24,07 & 25,18 \\
\hline 1 & 20,31 & 22,22 \\
\hline 2 & 19,55 & 18,52 \\
\hline 4 & 18,80 & 17,78 \\
\hline 8 & 18,80 & 16,30 \\
\hline 15 & 18,80 & 14,07 \\
\hline 30 & 18,80 & 11,85 \\
\hline 60 & 18,80 & 11,85 \\
\hline 120 & 18,05 & 11,11 \\
\hline 240 & 17,30 & 10,37 \\
\hline 480 & 17,30 & 9,63 \\
\hline 1440 & 15,79 & 8,15 \\
\hline
\end{tabular}

Conforme se observa na tabela 3, no intervalo entre 4 e 60 minutos, a porcentagem $(\% \mathrm{P})$ que passa $(<\mathrm{Di}) \mathrm{da}$ amostra A manteve-se constante em $18,80 \%$, enquanto na amostra B o valor sofreu um decréscimo. Concluiu-se que a amostra $\mathrm{A}$ apresentou componentes granulométricos de menor diâmetro em maior quantidade, ou seja, maior quantidade de argila e silte.

\subsection{Análise Mineralógica por Difração de Raios $X$}

Nas figuras 6 e 7, apresentam-se os resultados dos ensaios de DR-X. 


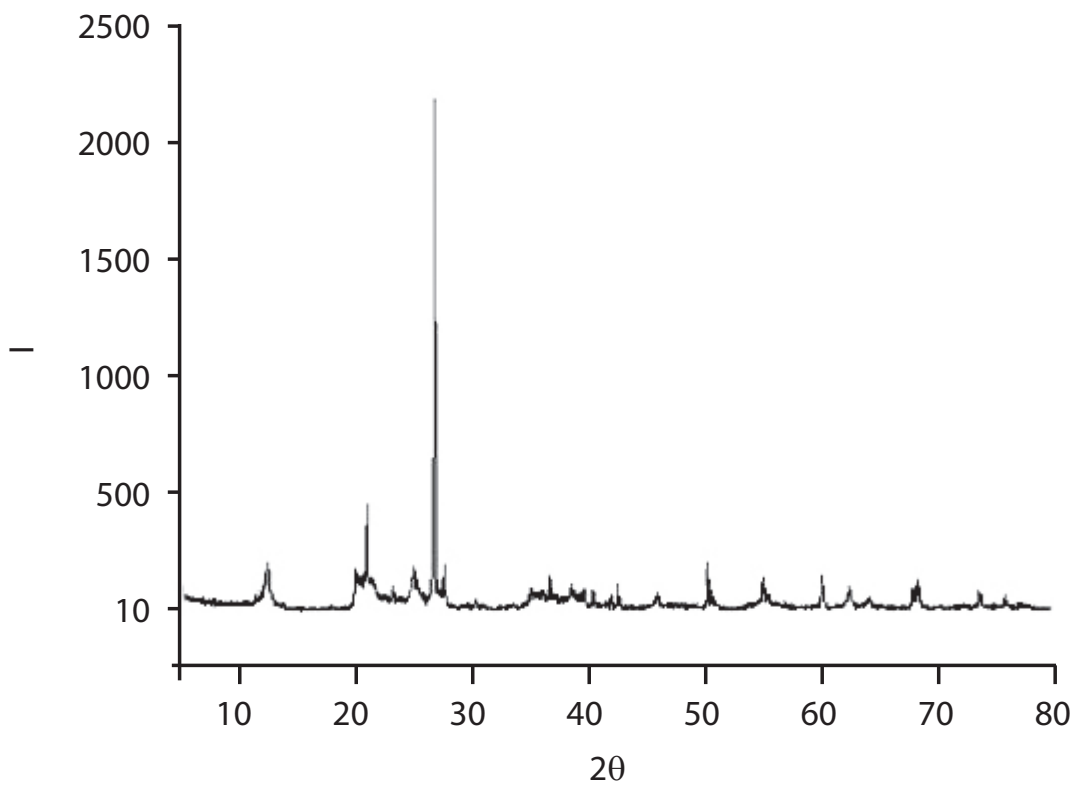

Figura 6. Difração de raios $x$ - amostra $A$.

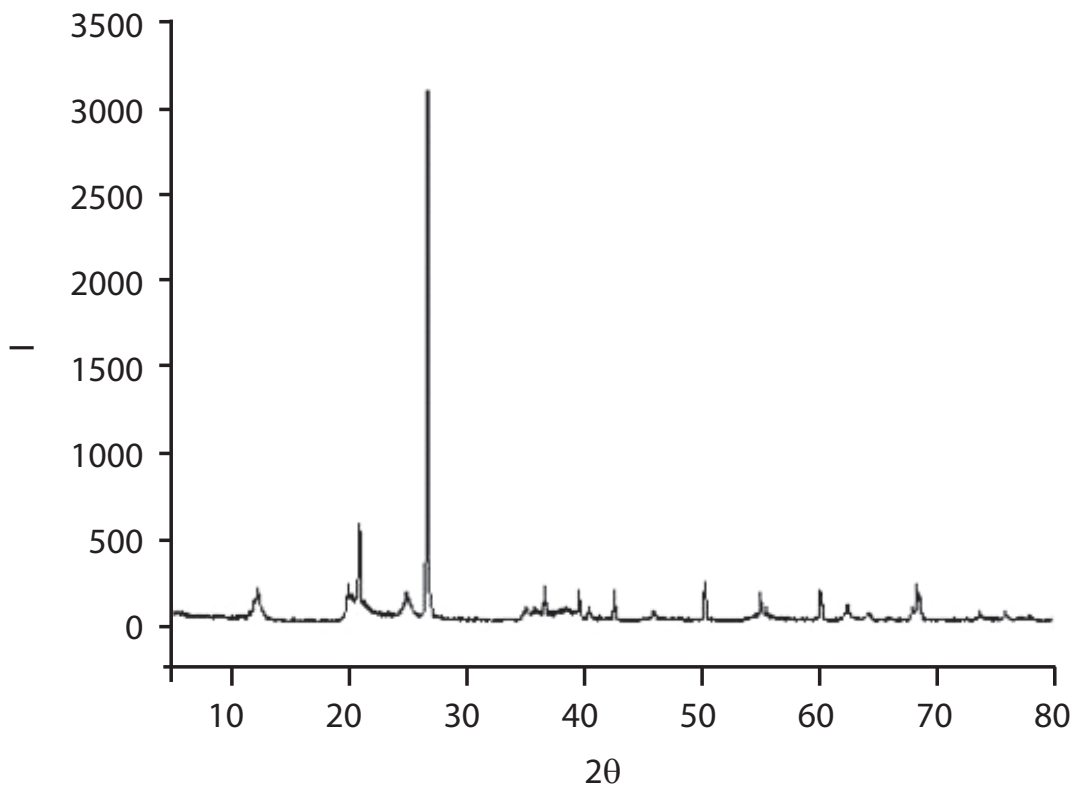

Figura 7. Difração de raios $x-\operatorname{amostra~} B$. 
Foi identificado que as amostras A e B apresentaram a mesma proporção de quartzo e caulinita, o que permite inferir que a argila A é a mesma utilizada na fabricação das habitações. O quartzo é o esqueleto da argamassa e sua presença diminui a necessidade de água. Por sua vez, a caulinita confere plasticidade e adesão à argamassa, enquanto a matéria orgânica presente nas amostras confere resistência mecânica em variaçóes negativas de temperatura e, junto à caulinita, contribui para permeabilidade do material.

\subsection{Limites de Liquidez (LL) e de Plasticidade (LP)}

Os valores estimados nos ensaios de limite de liquidez das amostras ficaram relativamente próximos: amostra $B=17 \%$ e amostra $A=20,5 \%$.

A amostra B apresentou limite de plasticidade de 10,7\% e índice de plasticidade de 6,3; enquanto a amostra $\mathrm{A}$ apresentou limite de plasticidade de $11 \%$ e índice de plasticidade de 9,5 .

\begin{tabular}{llll}
\hline Amostra & LL (\%) & LP (\%) & IP (\%) \\
\hline A & 20,5 & 11 & 9,5 \\
\hline B & 17 & 10,7 & 6,3 \\
\hline
\end{tabular}

A determinação do LL e LP de um solo objetiva o conhecimento da plasticidade do mesmo. A plasticidade consiste na maior ou menor capacidade de serem moldados, sob certas condiçóes de umidade e sem variação de volume; é indicada pelo "índice de plasticidade". Quanto maior o IP, mais plástico será o solo em determinadas condiçóes de umidade.

De acordo com as definiçóes e os resultados obtidos, concluiu-se que o solo da amostra B caracteriza-se como pouco plástico e arenoso, enquanto o da amostra A apresenta-se com plasticidade média e siltosa.

\subsection{Massa Específica}

A massa específica da amostra A ficou em $2,848 \mathrm{~g} / \mathrm{cm}^{3}$, enquanto da B o resultado foi de $2,891 \mathrm{~g} / \mathrm{cm}^{3}$. A diferença de cerca de $1,5 \%$ entre as amostras pode ser atribuída à presença de aditivo ou à maior presença de argila na amostra $\mathrm{A}$. Como o fator $\mathrm{K}$ de variação volumétrica em função da temperatura é igual para ambas, conclui-se que a amostra $\mathrm{B}$ apresentou maior 
teor de umidade (mais de 200\% de diferença) do que a amostra retirada in loco para medição. $\mathrm{Na}$ amostra $\mathrm{B}$, a variação do peso específico entre as diferentes amostras foi de 2,2\%; enquanto a amostra $\mathrm{A}$ apresentou uma variação de $1 \%$, indicando que no segundo caso a amostra era mais homogênea que no primeiro. De acordo com Pinto (2006), o peso específico de referência para os solos é $27 \mathrm{kN} / \mathrm{m}^{3}$, equivalente a uma massa específica de $2,646 \mathrm{~g} / \mathrm{cm}^{3}$. Nas nossas amostras consideradas no presente estudo, foram obtidos valores médios de $2,891 \mathrm{~g} / \mathrm{cm}^{3}$, no caso da amostra $\mathrm{B}$, e de $2,848 \mathrm{~g} / \mathrm{cm}^{3}$ para amostra $\mathrm{A}$, ou seja, números bem mais próximos aos $2,940 \mathrm{~g} / \mathrm{cm}^{3}$ do máximo comum apontado que dos 2,646 g/ $\mathrm{cm}^{3}$ do valor de referência. A amostra A apresentou um valor cerca de 7,63 \% maior do que o valor de referência, indicando uma quantidade de argila consideravelmente grande na amostra. Especificamente para a amostra B, essa afirmaçáo pode ser desconsiderada se for comprovada a existência de aditivo.

\section{Considerações Finais}

Os ensaios em laboratório que subsidiaram as análises realizadas neste estudo e que permitiram a caracterização do material constituem a etapa inicial para realização de outros estudos sobre características mecânicas e de durabilidade dos materiais, os quais fornecerão parâmetros que, paralelamente às análises in loco, possibilitarão elaborar critérios de avaliação da durabilidade do sistema construtivo em taipa de mão. Como resultado, podemos concluir que as amostras analisadas apresentaram boa qualidade, sendo a amostra natural - A caracterizada por maior homogeneidade e maior quantidade de argila, enquanto a amostra utilizada na construção das habitaçóes - B se caracterizou por apresentar maior umidade e possível presença de aditivos. Nas análises realizadas com base nos resultados dos ensaios, constatou-se que as amostras apresentaram quantidades similares de quartzos e caulinita, fato que permite afirmar que a argila da amostra - A é a mesma utilizada na fabricação das habitaçôes e que ela possui componentes granulométricos de menor diâmetro em maior quantidade (maior quantidade de argila e silte). A determinação desses parâmetros permitiu determinar se o material empregado nas edificaçóes foi adequado, contribuindo para adesão ao entramado de madeira e para a redução de trincas e estabilidade do solo na trama.

A experiência de quase 30 anos com a taipa de sebe em João Câmara demonstrou que requisitos técnicos foram considerados qualidade da matéria 
prima utilizada, dando uma clara ilustração da longevidade da técnica quando se parte da escolha apropriada de matéria prima. No entanto, o solo comum a todas as edificaçóes não impediu que algumas construçóes se apresentassem em estado de conservação precário. Notadamente o fator manutenção é uma variável primordial para a durabilidade e deve ser alvo de futuras investigaçóes.

\section{Agradecimentos}

À FINEP, aos bolsistas, ao Laboratório de Cerâmica - DEMAT / UFRN e ao Laboratório de Mecânica dos Solos, do Núcleo Tecnológico Industrial da UFRN.

\section{Referências Bibliográficas}

ARAÚJO, B. A. Recomendaçôes para melhoria tecnológica da vedação vertical em técnica mista em habitação de interesse social: Um estudo de caso no bairro do Alegre em São Sebastiāo do Passé. 2007. Dissertação (Mestrado) - Escola Politécnica, Universidade Federal da Bahia, Salvador. 2007.

ASSOCIAÇÃO BRASILEIRA DE NORMAS TÉCNICAS. NBR7181. Solo Determinação da Análise Granulométrica dos Solos. Rio de Janeiro, 1984.

ASSOCIAÇÃO BRASILEIRA DE NORMAS TÉCNICAS. NBR 6459. Solo Determinação do Limite de Liquidez.Rio de Janeiro, 1984.

ASSOCIAÇÃO BRASILEIRA DE NORMAS TÉCNICAS. NBR 7180. Solo Determinação do Limite de Plasticidade. Rio de Janeiro, 1984.

ASSOCIAÇÃO BRASILEIRA DE NORMAS TÉCNICAS. NBR 6508. Grãos de Solo que passam na peneira 4,8mm - Determinação da massa específica - Método de ensaio. Rio de Janeiro, 1984.

ASSOCIAÇÃO BRASILEIRA DE NORMAS TÉCNICAS. NBR 6457. Amostras de solo - preparação para ensaios e ensaios de caracterização. Rio de Janeiro, 1986.

CENTRO DE PESQUISAS E DESENVOLVIMENTO. PROGRAMA THABA Camaçari-BA. Manual de Construção com Solo-Cimento. São Paulo, 1984.

DANTAS, R. de C. Estudo bioclimático das habitaçóes do Projeto Taipa em João Câmaral $R N$ : ênfase no desempenho térmico. 2002. 149f. Dissertação (Mestrado em Arquitetura e Urbanismo) - Centro de Tecnologia, Universidade Federal do Rio Grande do Norte, Natal. 2002.

DOAT, P et al. Construire en terre. Ed. Centre de Reserche et d'application - Terre. ed. 1. France. 1979.

HUNTER K.; KIFFMEYER D. Earthbag Building: Tools, Tricks and Techniques. New Society Publishers, 2004. 
MINISTÉRIO DO EXÉRCITO, COMANDO MILITAR DO NORDESTE MECMN- 1o GRUPAMENTO DE ENGENHARIA. Destacamento João CâmaraDJC. Projeto Taipa, especificaçóes. João Câmara, 1987. 13 p.

LIMA, R. do C. de O. Estudo da durabilidade de paredes monoliticas e tijolos de solo-cimento incorporados com residuo de granito. 2010. 109p. Dissertação (Mestrado em Engenharia Civil e Ambiental) - Centro de Tecnologia e Recursos Naturais, Universidade Federal de Campina Grande. 2010.

MINKE, G. Building with Earth, Design and Technology of a Sustainable Architecture. Birkhäuser - Publishers for Architecture. 2006.

PINTO, C. S. Curso Básico de Mecânica dos Solos. $3^{a}$ ed. São Paulo: Oficina de Textos, 2006.

PINTO, E. M.; NEGREIROS, B. A.; VIEIRA, C.; SOUZA, A. H. Rammed Earth Homes Built In Northeast Brazil as an Emergency Housing Policy. In: Earth USA 2013 -Seventh International Conference on Architecture and Construction with Earthen Materials. 4-6 October, 2013. Santa Fe, New Mexico, USA. 2013.

PISANI, M. A. J.; CANTEIRO, F. Taipa de mão: história e contemporaneidade. AEDIFICANDI Revista de Arquitetura e Construção, São Paulo, v. I, n. 2, p. 1-21, 2006.

RICARDO, U. Um Material de Construcción al Alcance de Todos, Métodos Modernos de Construcción com Terra, Experiencia. Centro de Referencia Del Habitat, 2003.

SILVA, M. S. D. A Terra Crua como Alternativa Sustentável para a Produção de Habitação Social. 2001. 60f. Dissertação (Mestrado) - Escola de Engenharia de São Carlos, Universidade de São Paulo, São Carlos. 2001.

VELOSO, J. A. V. O Terremoto que Mexeu com o Brasil. $1^{\text {a }}$ ed. Brasília: Thesaurus Editora, 2012. 342p. 
